\title{
A Identidade Cultural da Tribo Yawanawá no Design dos Produtos
}

\author{
The Cultural Identity of the Yawanawá Tribe in Product Design
}

GHASEMI BOROON, Mahshid; Pós-graduanda em Design; Universidade de Brasília mahshidgh.boroon@gmail.com

MAGALHÃES VIANA, Dianne; DSc.; Universidade de Brasília

diannemv@unb.br

\section{Resumo}

Neste artigo, foi estudado o papel da identidade cultural no design de produto, considerando a cultura, crenças, técnicas e materiais dos Yawanawá. Para tanto, foi realizada uma pesquisa bibliográfica na qual foram estudadas as definições e implicações da cultura e do design e a interação entre elas. E em seguida, examinados os produtos baseados na cultura Yawanawá para avaliar a potencialidade do design baseado na cultura. $O$ objetivo deste artigo é verificar a partir do estudo da cultura Yawanawá a possibilidade de desenvolvimento de novos produtos e o papel do designer nessa tarefa. Isso pode contribuir para o desenvolvimento do design brasileiro e também aproximar diferentes culturas. De fato, os países multiculturais podem ser mais poderosos no design de base cultural, já que a linguagem é a mesma e a comunicação entre diferentes culturas pode ser mais fácil.

Palavras Chave: Identidade cultural; Design de Produtos; Yawanawá.

\begin{abstract}
In this paper, the role of cultural identity in product design was studied, considering the culture, beliefs, techniques and materials of the Yawanawá. In order to do that, a bibliographical research was carried out in which the definitions and implications of the culture and the design and the interaction between them were studied. Then the products based on Yawanawá culture were examined to assess the potentiality of culture-based design. The purpose of this study is to verify if the use of Yawanawa culture can be a pathway towards the application of different cultures in the design of products. This can contribute to the development of Brazilian design and also bring people together by introducing different aspects of their cultures to other parts of the country. In fact, multicultural countries can be more powerful in cultural-based design, since the language is the same and communication between different cultures may be easier.
\end{abstract}

Keywords: Cultural identity; Product Design; Yawanawá. 


\section{Introdução}

Neste artigo são apresentados alguns aspectos da cultura de uma das tribos indígenas do Brasil, denominada Yawanawá pelos vários designers (Marcelo Rosenbaum, Mariazinha, Letícia Borge, etc). "O nome Yawanawá significa, literalmente, Povo do Queixada". Essa tribo mora em floresta amazônica no leste do estado do Acre perto das margens do Rio Gregório, município de Tarauacá. Eles sempre mantiveram todos os costumes, a tradições e a linguagem de seus ancestrais, e estão tentando preservar seus conhecimentos e idéias. A floresta é sagrada do ponto de vista deles porque os abriga e fornece sua comida e acaba por amá-los. Eles são "o primeiro povo a conseguir reconhecimento do estado do Acre e oficializar seu território no Brasil" (ROSENBAUM, 2013. BORBA, 2016). Esses designers depois de pesquisar as tradições e as crenças da tribo yawanawá com a utilização da cultura deles como os kenês, desenhos que representam histórias, animais e plantas sagradas, projetaram e comercializaram produtos.

O objetivo deste artigo é verificar a partir do estudo da cultura Yawanawá a possibilidade de desenvolvimento de novos produtos e o papel do designer nessa tarefa. Isso pode contribuir para o desenvolvimento do design brasileiro e também aproximar diferentes culturas. Podem ser produzidos os produtos baseados na cultura o que resulta na criação de fenômenos estéticos com significados profundos (MOALOSI, 2008, SATO, 2008, ROSENBAUM, 2013). A importância deste artigo é mostrar que as culturas indígenas, têm muito a contribuir mesmo sendo pouco retratadas e ficando à margem comparadas com outras culturas (Marcoviz and Oliveira, 2010; Muniz, 2015), no design dos produtos.

\section{Cultura e Design}

Segundo Cunha (2017, pp. 354 e 355),

... o termo "cultura", em seu uso antropológico, surgiu na Alemanha setecentista e de início estava relacionado à noção de alguma qualidade original, um espírito ou essência que aglutinaria as pessoas em nações e separaria as nações uma das outras. (...) essa originalidade nasceria das distintas visões de mundo de diferentes povos.

A autora destaca nessa noção de cultura, o sentido de autoria intrínseca desses povos, o qual ainda permanece nos dias de hoje. Destaca também que "o uso de cultura tem um efeito coletivizador: todos a possuem e por definição todos a compartilham" (CUNHA 2017, p. 363).

Entretanto, questiona a aplicabilidade universal desse pressuposto, tendo em vista as diferenças entre o que muitas sociedades tradicionais entendem por essa autoria. Nesse sentido conceitua duas esferas de cultura, uma interétnica e uma interna.

De outro modo, para se ter um melhor entendimento da cultura, é necessário que, primeiro, a cultura produza diversidade e variedade, e segundo, que a cultura afete naturalmente os comportamentos humanos (DAHL, 1999).

A despeito de tratarmos aqui da cultura de um grupo com conhecimentos tradicionais, habitantes de uma área geográfica particular, de acordo com Sato e Chen $(2008$, p.1) a cultura "... pode emergir de qualquer segmento populacional". Nesse sentido, cultura é um fenômeno multifacetado que se manifesta a partir do compartilhamento de pensamentos, sentimentos e formas de viver em uma sociedade. Ainda, segundo esses autores, 
estética, regras, normas e valores que os membros do grupo compartilham. Culturas diferentes, portanto, produzem diferentes artefatos e ambientes baseados em suas características culturais. Por outro lado, os artefatos, através das interações das pessoas com eles, influenciam as culturas e podem até mesmo produzir uma nova cultura. (Sato e Chen, 2008, p.1, tradução nossa).

Para Moalosi, Popovic e Hickling-Hudson (2010, p. 175) a cultura "é naturalmente revelada em toda ação humana, incluindo os produtos que as pessoas projetam".

Papanek (1984) afirma que os objetos projetados para realizar um simples trabalho prático, tornam-se em ferramentas para analisar culturas.

Nesse sentido, Moalosi et al. (2010), apontam uma relação entre cultura e design, lembrando também que a civilização foi estudada com base na evolução dos objetos tendo em vista os atributos culturais incorporados nesses objetos.

No design baseado na cultura, deve-se envolver o valor histórico e os valores dos usuários nos produtos. Outrossim, a cultura e os valores inerentes a ela são instrumentos de inspiração valiosos para novas ideias de design. No entanto, em se tratando de diferentes culturas, deve-se encontrar conexões entre esses valores.

Cavalcanti (2001) define o conceito de cultura em duas partes, uma parte é chamada de cultura material que inclui todas as objetivações materiais (artefatos), e a outra é chamada de cultura não material que inclui todas as maneiras emocionais, intelectuais e práticas que são aprovadas pela próprias sociedade. Nesse sentido, um produto pode ser entendido como uma coleção de características estéticas e simbólicas.

Montaña (2004) acredita que a existência de valores culturais em produtos leva a estimular o sentimento do consumidor e consequentemente leva a aumentar o grau de reconhecimento e consciência do consumidor sobre o produto. Para criar uma concorrência entre produtos, a formação desse tipo de relação emocional entre o consumidor e o produto pode ser necessária. A vantagem da existência de valores culturais consiste na criação de produtos exclusivos, que são difíceis de imitar.

Nessa perspectiva, o Design pode contribuir para essa distinção, por meio da pesquisa de raízes culturais, materiais e métodos de produção diferenciados e atributos que possam ser incorporados a este produto.

O Brasil possui uma diversidade de recursos naturais, etnias e culturas. Essas diferenças culturais são manifestadas na música, dança, culinária, artesanato, hábitos e costumes. Este arcoíris cultural pode ser usado para projetar e fabricar novos produtos. Ou seja, pode-se usar a cultura ligada à origem de uma região geográfica ou outras manifestações de comunidades como inspiração para a criação de objetos e artesanatos exclusivos com os produtos naturais e matériasprimas encontradas nessa região.

Em relação ao uso de conhecimentos tradicionais - que envolvem saberes e costumes transmitidos de geração a geração em comunidades indígenas ou outras específicas -, no que diz respeito a recursos genéticos, a propriedade é coletiva e o acesso é controlado para evitar apropriação indevida para fins econômicos por meio do sistema de propriedade intelectual (JUNGMANN, 2010).

Feitas as considerações até aqui, cabe colocar as seguintes questões: Como a identidade 
cultural indígena pode ser incorporada a produtos destinados ao mercado de consumo? Como utilizar a cultura indígena como inspiração para o design de produtos? E o resultado disso, teria um efeito reflexivo na cultura indígena?

Acerca da identidade cultural na concepção sociológica, Hall $(1997$, p.11) afirma que esta "Preenche o espaço entre o "interior" e o "exterior" - entre o mundo pessoal e o mundo público". Ou seja, "a formação da identidade se dá a partir da interação entre o indivíduo e o mundo, manifestando-se em diferentes espaços e diferentes instâncias sociais" (GONÇALVES, 2013). Infere-se que a cultura interétnica acabaria por afetar as identidades culturais envolvidas, em um processo de renovação.

Ao considerar a identidade cultural no design de produtos, o designer é capaz de transferir a tecnologia e a cultura juntas e reduzir a lacuna entre elas no processo criativo. Desta forma, o designer pode coadjuvar, como afirmam Krucken (2009, p.48) e Cavalcante (2014), atuando como "facilitador ou agente ativador de inovações colaborativas, promovendo interações na sociedade", "sendo flexível, integrador, sem intervir nas especificidades culturais das comunidades" (CAVALCANTE, 2014, p.36).

Por exemplo, Bastian (2013) declara, acerca de um projeto de luminárias junto à tribo Yawanawá:

Marcelo Rosenbaum no projeto As Luminárias da coleção Yawanawá enfatiza a utilidade do design: Design útil é aquele que transcende o objeto. considerando a palavra útil, Rosenbaum afirma que é mais do que a função prática, as peças sob esse conceito devem atender a um propósito maior.

Nesse projeto, os designers utilizaram miçangas, como pontua Castro (2014): "O uso deles de miçangas não é só pela questão visual e estética, mas também pela sua utilidade, funcionalidade, consciência ecológica, social e cultural".

Acerca da aceitação do produto artesanal, Castro (2014) explica:

(...) apesar do todo este potencial, há resistência de um mercado de alto giro para as luminárias que utilizam o artesanato em sua concepção. De acordo com a designer Adriana Fernandes, gerente de desenvolvimento de produtos na empresa La Lampe, que possui sede em São Paulo e comercializa seus produtos em 13 lojas distribuídas pelo Brasil, e que acompanhou o projeto da Coleção Yawanawá em 2013, luminárias com estas características de materiais, ou com um processo de fabricação artesanal, se mostram inviáveis para um mercado de alto giro. (informação verbal). Sendo assim, é preciso buscar em quais outros aspectos estas peças artesanais podem trazem de relevância para a lluminação, ou seja, para o Design e assim motivar as empresas a investir em projetos deste tipo.

De acordo com Ferreira (2002), “Na minha opinião, a identidade será a força de inovação mais importante no desenvolvimento do design de produto".

Considerando-se a cultura no design do produto, além da tecnologia, materiais e métodos de produção diferenciados, são incorporados valores ao produto, que podem ser significativos para o usuário.

\section{Produtos Considerados}

\subsection{Luminárias da Coleção}

O designer Rosenbaum, juntamente com um grupo de 30 pessoas, alojou-se nas aldeias de 
Nova Esperança e Amparo, na Floresta Amazônica, em 2013, no escopo de projeto denominado AGT (Gente Transforma). A ideia deste projeto foi formada através da troca de conhecimentos entre designers e indígenas da tribo Yawanawá, tendo em vista a sustentabilidade da cultura Yawanawá e a promoção do desenvolvimento local. O design das luminárias (Figura 1) foi inspirado pela cultura, crenças, mitos, cosmologia e técnicas artesanais da tribo (Bastian, 2013).

Com este projeto, Rosenbaum almejou demonstrar o design útil e também como ferramenta de comunicação:

Hoje a gente enxerga o design útil como um movimento e uma forma de imaginar o design como um catalisador de mudanças para o redesenho de um novo mundo. Então, quando a gente começa a pensar nisso, percebe que o design não está mais só no objeto, no fazer as coisas materiais, uma mesa, uma cadeira - ele transcendeu isso. A ancestralidade entende que uma ideia não é de um indivíduo, mas de um coletivo. A pessoa está apta a receber aquela informação, mas para o bem comum. (Bastian, 2013).

Figura 1: Luminárias da coleção Yawanawá: (a) Pendente Runuãrunuahu: "jiboias pequenas", (b) Pendente Runuãkenê, o design inspirado em animal sagrado e, (c) Pendente Shinuã solitário, de miçangas trançadas à mão.

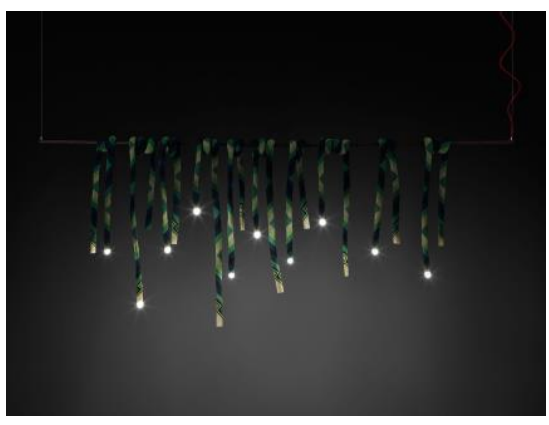

(a)
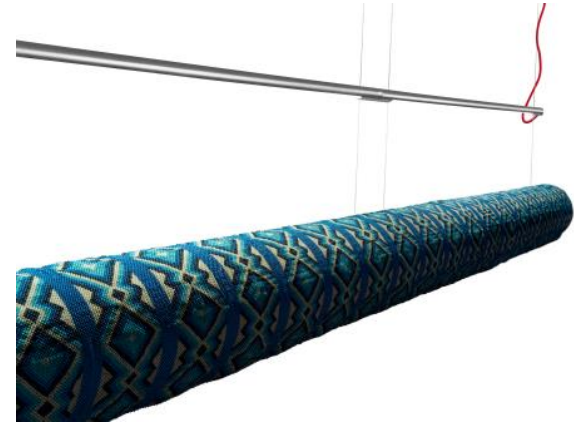

(b)

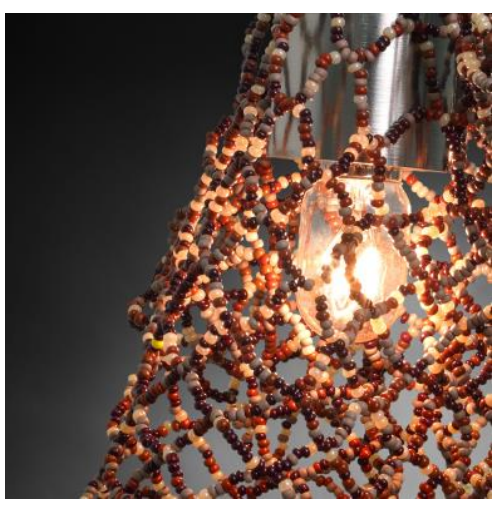

(c)

Fonte: rosenbaum.com.br (2018)

As luminárias produzidas são especificamente baseadas dos mitos da tribo Yawanawá. A diferença étnica entre indígenas brasileiros pode ser maior do que a que existe entre a cultura japonêsa e francesa ou entre a cultura iraniana e alemã. A contribuição desse projeto para os indígenas foi dar-lhes auto-estima (Bastian, 2013). 
"porque o que a gente leva a eles é um olhar do que eles já têm, de muitas vezes negação ou de não valorização. E aí, quando eles fazem e esse produto é aceito, esse produto tem exatamente a ver com eles. O nosso movimento é exatamente esse: pensar em quem vai produzir e em quem vai consumir e de que forma - esse é o movimento do design útil." (Bastian, 2013).

\subsection{Design de Roupas Baseado na Cultura da coleção Yawanawá}

\subsubsection{Sonhos Yawanawá}

A Coleção de Sonhos Yawanawá, mostrada na Figura 2, é uma coleção de roupas coloridas e descontraídas, proposta pela cacique Mariazinha Yawanawa. O design das roupas foi inspirado nas pinturas de Kenês, inclusive a variedade e o padrão de cores. Acessórios de artesanato feito com miçangas e plumas, são utilizados para valorizar as roupas (Agazeta Doacre, 2017).

Figura 2: Sonhos Yawanawá.

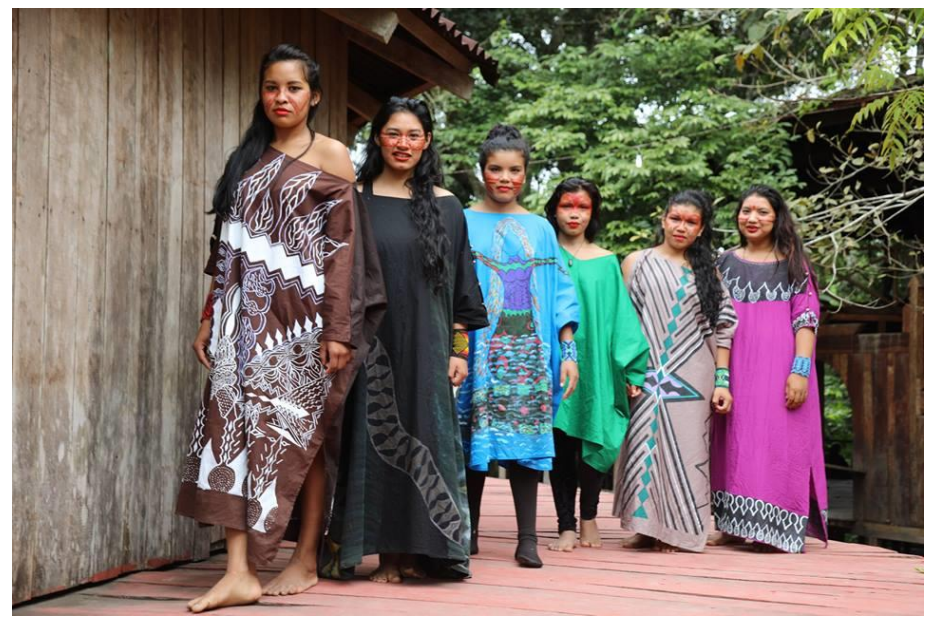

Fonte: agazetadoacre.com (2017)

\subsubsection{Yawanawá por Laeticia}

Letícia Borges, uma advogada especializada em direitos indígenas, em 2009, depois de ver a coleção de Armani que foi inspirada em motivos tribais e também a coleção Gucci, decidiu criar uma moda baseada no trabalho e cultura da tribo Yawanawá. De acordo com Letícia, "Cada tribo tem características culturais próprias. Já os Yawanawá tem uma característica estética muito forte, de miçangas, pintura corporal, penas, símbolos". A marca dela se chama Yawanawá por Laeticia, e seu plano é criar coleções sazonais de projetos baseado em arte tribal. Letícia concentrou-se também, na primeira parte do seu trabalho, nos desenhos tradicionais desta tribo, denominados kenês, que foram realizados com miçangas pelas mulheres da tribo. A Figura 3 apresenta um desenho adaptado da coleção, indicando a aplicação do kenê. (Lilian Pacce, 2013).

Figura 3: Bordado em miçanga que representa cabeça de cobra 

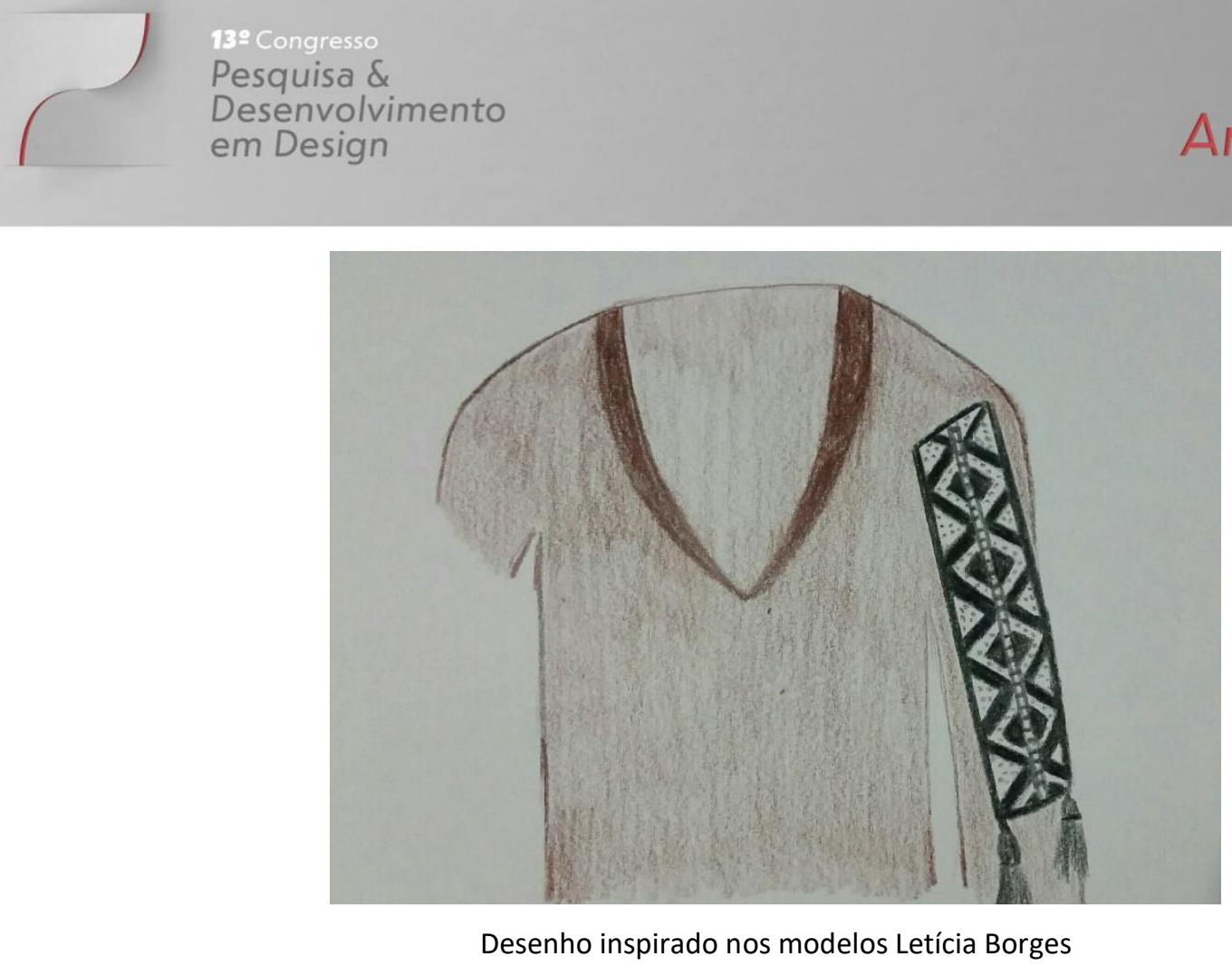

\subsubsection{Cavalera e Ritual Indígena}

O designer Alberto Hiar, para criar sua coleção de verão da Cavalera e para buscar inspiração na cultura indígena, visitou a tribo Mutum da etnia Yawanawá na Floresta Amazônica. Alberto alega que "a Marca Cavalera sempre fala sobre a cultura e comportamento brasileiro, as coisas que estão em nossa história e os momentos em que vivemos". O resultado por si mostra "o estilista justificando sua escolha e o motivo pelo qual quis ir tão longe". O designer, além da inspiração da cultura tribal, quando voltou, trouxe alguns índios para compartilhar suas experiências com seu público. Os modelos, numa simulação de um ritual, surgiam com roupas desenhadas com base na cultura indígena. Conta Alberto "Olhamos pra formigas, cupinzeiros e sentimos que aquilo poderia virar referência para nossa coleção, mas o que nós nos aprofundamos mais foram nos kenês, que são os desenhos que eles usam pra fazer os acessórios e adornos" (Belley, 2015).

\subsection{Os Tapetes Inspirados pela Cultura Indígena}

Segundo Bastian (2017): "O contraste entre a forma orgânica da pele bovina e a geometria das pinturas é o destaque dos tapetes estampados Pelle, recém-lançados por Maraí Valente".

Quando Maraí participou do curso Design Essencial de Marcelo Rosenbaum, sua mente se abriu sobre essa questão. Maraí descobriu que "a beleza está no olhar da pessoa, e não na matéria. É no que aquela peça te traz, de inspiração, de sentimento" (Bastian, 2017).

Durante esse processo, a atenção de Maraí foi atraída para um índio, "que pintava aqueles desenhos que aparecem nas pulseirinhas de miçanga (e que são a representação de elementos da natureza, como árvore, pássaro, etc) em bambus, roupas e outros suportes" (Bastian, 2017).

Quando Maraí voltou para São Paulo, decidiu pintar num pedaço de pele os desenhos inspirados na cultura da tribo Yawanawá. O resultado agradou, então ela começou a experimentar com peles maiores, outros desenhos e outras cores. Essa coleção, inclui quatro estampas geométricas: Borboleta, Mirações, Onça e Escamas, Figura 4. 
Figura 4: Tapetes baseado na cultura indígenas (Yawanawá). (a) Modelo Borboleta, (b) Modelo Escamas

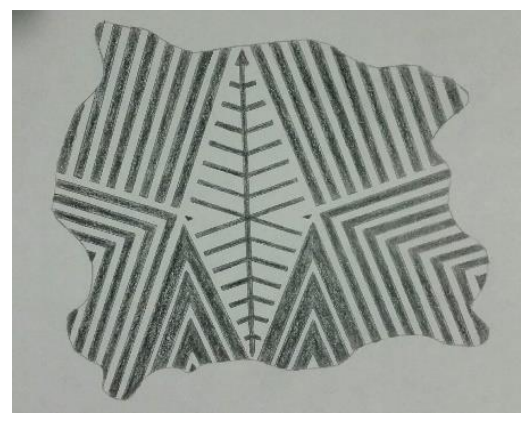

(a)

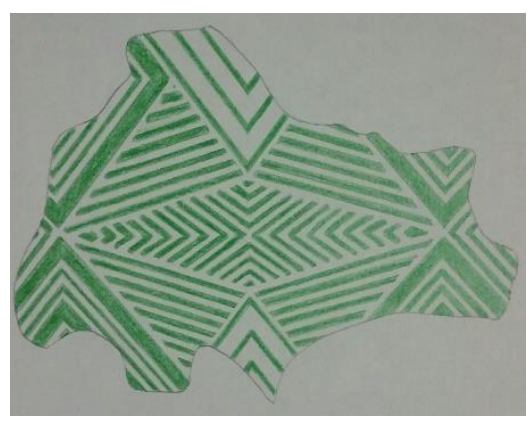

(b)

Desenho inspirado do design Maraí Valente

\section{Considerações Finais}

Quando um produto é projetado com base na cultura e nas crenças de uma comunidade, não é somente um mero objeto, que pode ser uma obra de arte. O sentimento e a compreensão por trás do design deste tipo do produto deixa uma parte da cultura ou tradição de uma comunidade ou tribo ser colocado na forma de um objeto. $O$ olhar do consumidor em relação ao produto projetado, além da sensação de aliviar a necessidade, pode ser um profundo olhar com compreensão. O produto baseado na cultura possui identidade. Por exemplo, todos os produtos apresentados neste artigo, além da funcionalidade (luzes, roupas, tapetes), são bem conhecidos pelo design usado, característico dos povos indígenas da tribo Yawanawá, no Brasil.

Finalmente, se os designers levarem em conta as tradições, as crenças e a cultura da sua sociedade no design dos seus produtos, podem inconscientemente encorajar a sociedade a valorizar e preservar suas tradições e cultura. Conclusões

Ao utilizar a cultura de Yawanawá no design de produtos, eles tiveram a oportunidade de apresentar sua cultura visualmente à sociedade brasileira na forma de novos produtos. Isso permite acentuar algumas partes de sua cultura não evidenciadas antes.

Utilizando o conhecimento de designers no design do produto desejado, os materiais e técnicas para construí-los e também as crenças e cultura dos Yawanawá, um compartilhamento de conhecimento foi criado entre eles.

Quando a cultura Yawanawá é integrada ao design do produto, o produto final não é apenas um objeto, mas inclui um conjunto de conceitos, técnicas e materiais. Isso significa um novo produto com aspectos estéticos.

\section{Referências}

PACCE,L. Geometrias indígenas em nova marca. In: LILIAN PACCE, 2017. (https://www.lilianpacce.com.br/moda/yawanawa-por-laeticia-geometrias-indigenas/). (23 de Outobro de 2013).

PIMENTELRBR, J. Conheça mais peças da coleção indígena Sonhos Yawanawa. In: agazeta.net, 2017. (http://www.agazeta.net/entretenimento/gazeta-estilo/item/2973-gazeta-estilo-27-06-17). (17 de Junho de 2017). 
BASTIAN, W. As luminárias da coleção Yawanawá. In: : Casa Vogue, 2017. (https://casavogue.globo.com/MostrasExpos/noticia/2013/04/colecao-yawanawa-de-marcelorosenbaum.html). (02 de abril de 2013).

BASTIAN, W. Maraí Valente cria tapetes inspirados pela cultura indígena. In: Casa Vogue, 2017. (http://casavogue.globo.com/Colunas/Design-Do-Bom/noticia/2017/02/marai-valente-criatapetes-inspirados-pela-cultura-indigena.html). (17 de Fevereiro de 2017).

BELLEY, M. Cavalera une desfile de moda e ritual indígena. In: Estadão, 2017. (http://emais.estadao.com.br/noticias/moda-e-beleza, cavalera-une-desfile-de-moda-e-ritualindigena,1669151). (13 de Abril de 2015).

BORBA, M. d. A sorça do coração da floresta. In: A alquimia da cura, 2017. (https://aalquimiadacura.blogspot.com/2016/06/yawanawa-i-forca-do-coracao-da-floresta.html). (5 de junho de 2016).

CASTRO, A. C. da. Iuminárias Brasileiras. In: revista da Belas Artes, n.o 12. P. 8-9, set 2015.

CAVALCANTE, A. L. B. L. Design para a Sustentabilidade Cultural: Recursos Estruturantes para Sistema Habilitante de Revitalização de Conhecimento Local e Indígena. Tese. Programa de PósGraduação em Engenharia e Gestão do Conhecimento. Universidade Federal de Santa Catarina. Florianópolis, 2014. P. 321.

CAVALCANTI, V. P. O Design do Móvel Contemporâneo Brasileiro: da diversidade a especificidade. São Paulo, 2001. P.27.

COMMITTE, t. P. Definition of Industrial Design. In: World Design Organization (WDO) ${ }^{\mathrm{TM}}, 2017$. (http://wdo.org/about/definition/). (17-18 de October de 2015). the 29th General Assembly in Gwangju (South Korea).

CUNHA, M. da. Cultura com aspas e outros ensaios. Coleção Ensaios (Português) Capa Comum, 2009

DAHI, S. Intercultural Research: The Current State of Knowledge. Middlesex University Discussion Paper. n. 26. Set 2004. Available from SSRN: http://ssrn.com/abstract=658202 [Accessed 12 January 2004).

FERREIRA, J. c. Design e Identidade Cultural: Caso de Estudo sobre o projecto "Marinha Grande MGlass". Porto: Disserta- ção de Mestrado em Design de Produto pela Faculdade de Engenharia da Universidade do Porto (FEUP/ESAD), 2002. p.25.

GONÇALVES, K. R. Identidade Cultural Indígena: Interpretações da Obra História de Indios. Monografia. Porto Alegra: Universidade Federal do Rio Grande do Sul, 2013. p. 61.

GUTIERREZ, M. J. Design e Herança Cultural. Lisboa: Universidade Técnica de Lisboa. 2011

HALL, Stuart. A identidade cultural na pós-modernidade. Rio de Janeiro: DP\&A Editora, 1997. HESKETT, J. Toothpicks and Logos: Design in Everyday Life. New York: Oxford University Press, set 2002.

JUNGMANN, Diana de Mello. A caminho da inovação: proteção e negócios com bens de propriedade intelectual: guia para o empresário /Diana de Mello Jungmann, Esther Aquemi Bonetti. - Brasília: IEL, 2010. 125 p.: il. ISBN 978-85-87257-49-9. 
KRUCKEN, Lia. Design e território: valorização de identidades e produtos locais. São Paulo: Studio Nobel, 2009.

MOALOSI, R. P.-H. Culture-orientated product design. International Journal of Technology and Design Education, p.175-190, set 2008.

MONTAÑA, J. (2004 p.35). Design, a cultural career. In: The White Book. [s.I.], BEDA.

MUNIZ, M. A. (21st June 2015). A influência do índio na busca da identidade brasileira. (p. 1). http://lacerdaletras.blogspot.com.br/2015/06/a-influencia-do-indio-na-busca-da.htm.

OLIVEIRA, C. M. A questão Indígena e a Identidade cultural. In: Anais do $3^{\circ}$ Salão de Extensão e Cultura da UNICENTR, 20 a 25 de setembro de 2010

PAPANEK, V. Design for the real world : human ecology and social change. New York: Van Nostrand Reinhold, 1984. P.39.

PAYNE, M. A Dictionary of cultural and critical theory. Oxford: Blackwell, 1999.

ROSENBAUM, M. A força da floresta YAWANAWÁ. In: Rosenbaum, 2017. (http://rosenbaum.com.br/projetos/yawanawa/localizacao/).

SATO, K., \& CHEN, k. Special Issue Editorial: Cultural Aspects of Interaction. (2008). International Journal of Design, 1-3. 